Iberian Journal of the History of Economic Thought

ISSN-e: 2386-5768

http://dx.doi.org/10.5209/ijhe.65959

\title{
Milton Friedman y el monetarismo en la teoría y en la práctica
}

Antonio Argandoña ${ }^{1}$

Recibido: 07/10/2019/ Aceptado: 12/02/2020

Resumen. El pensamiento monetarista se fue formando a partir de los años 1950, de la mano de Milton Friedman, Karl Brunner, Allan Meltzer y otros conocidos economistas; alcanzó su mayor esplendor en los años 1970, cuando se enfrentó con el keynesianismo como explicación de las fluctuaciones económicas y la inflación, ejerciendo una notable influencia en el diseño y la aplicación de la política monetaria. Las circunstancias económicas de los años 1980 le hicieron perder relevancia, pero el monetarismo sigue vigente en la actualidad, a través de numerosas ideas que están recogidas en los modelos macroeconómicos y en el trabajo de los bancos centrales, y que la crisis financiera reciente y la Gran Recesión no han hecho sino acrecentar.

Términos clave: Karl Brunner; dinero; Milton Friedman; Allan Meltzer; monetarismo; política monetaria

Clasificación JEL: E3, E4, E5

\section{[es] Milton Friedman and monetarism in theory and in practice}

Abstract. The monetarist thought was formed from the years 1950, by the hand of Milton Friedman, Karl Brunner, Allan Meltzer and other well-known economists; it reached its greatest splendor in the 1970s, when faced with Keynesianism as an explanation of economic fluctuations and inflation, exerting a notable influence in the design and application of monetary policy. The economic developments of the 1980s made him lose relevance, but monetarism is still in force today, through numerous ideas that are reflected in the macroeconomic models as well as in the work of central banks, and that the recent financial crisis and Great Recession have only increased.

Keywords: Karl Brunner; Money; Milton Friedman; Allan Meltzer; Monetarism; Monetary Policy

JEL classification: E3, E4, E5

Sumario: 1. Introducción. 2. Auge y declive del monetarismo. 3. Las tesis monetaristas. 3.1. La estabilidad de la economía. 3.2. El dinero y la teoría cuantitativa. 3.3. Neutralidad del dinero. 3.4. El intercambio entre inflación y empleo. 3.5. Tipos de interés nominales y reales. 3.6. Las expectativas. 3.7. El mecanismo de transmisión. 3.8. La política monetaria. 3.8.1. El marco institucional y operativo. 3.8.2. Objetivos y reglas. 3.9. Los modelos monetaristas. 4. Teorías y políticas post-monetaristas. 4.1. La política monetaria post-monetarista. 4.1.1. Objetivos y reglas. 4.1.2. Los instrumentos. 4.1.3. La política monetaria en la crisis financiera. 4.2. El postmonetarismo en la teoría macroeconómica. 4.2.1. Expectativas racionales y nueva economía clásica. 4.2.2. La Nueva Economía Keynesiana y la Nueva Síntesis Neoclásica. 5. Conclusiones. Referencias.

Cómo citar: Argandoña, A. (2020): "Milton Friedman y el monetarismo en la teoría y en la práctica" en Iberian Journal of the History of Economic Thought 7(1), 29-43.

\section{Introducción}

La escuela monetarista se fue formando a partir de los años $1950^{2}$, con Milton Friedman como su figura principal; de ella formaron parte economistas prestigiosos como Karl Brunner, Allan Meltzer, Philip Cagan, David Laidler, Michael Parkin, Alex Cukierman, Alan Walters y otros ${ }^{3}$.

El monetarismo subraya la importancia del dinero en las fluctuaciones del producto y de los precios (Cagan 1987, Mayer y Minford 2004). Ahora bien, si el mensaje del monetarismo es solo este, su influencia debió ser muy reducida. Y no es así. Meltzer (2004, 161) afirmaba hace unos años que "la mayor parte del análisis monetarista forma ahora parte central de lo que se llama (extrañamente) el modelo neokeynesiano". Y cincuenta años después del discurso de Friedman (1968a) como presidente de la American Economic Association, un texto que marcó "un punto de inflexión en la historia de la investigación macroeconómica (...), es notable que sus temas sigan siendo centrales en el estudio de los ciclos económicos y la política monetaria" (Mankiw y Reis 2018, $82,92)$. Lo que no quiere decir que los monetaristas

Profesor Emérito, IESE Business School, Universidad de Navarra OICID: https://orcid.org/0000-0002-4783-5668

2 Con precedentes en Irving Fisher y los teóricos cuantitativistas, Warburton, Keynes y algunos maestros de Friedman en Chicago, como Simons, Knight, Viner y Mints; cfr. Argandoña (1981), caps. 1 y 2.

Brunner (1968) dio nombre a la escuela. 
sigan atrayendo hoy la atención de los académicos, quizás porque desarrollaron sus ideas al compás de los problemas de su época, y por eso resulta difícil entenderlas en el entorno actual (Hetzel 2017, 2).

El monetarismo no es un credo monolítico, y no se estableció de una vez para siempre. Friedman afirmaba que "la teoría ha de ser juzgada por su poder predictivo para la clase de fenómenos que se piensa puede explicar" (1953a, 8), y estaba dispuesto a cambiar su manera de pensar si la evidencia empírica le movía a hacerlo ${ }^{4}$.

Este trabajo tiene por objeto presentar las líneas principales del monetarismo y su impacto en el pensamiento académico y en la política económica. Muchas de sus afirmaciones se encuentran también en economistas de otras escuelas, pero lo que ellos aportaron fue, principalmente, un fundamento sólido y la coherencia en sus mensajes. Explicaremos primero su evolución en el tiempo; luego, sus tesis principales y su proyección en la teoría y la política recientes, para acabar con las conclusiones.

\section{Auge y declive del monetarismo}

El monetarismo evolucionó al compás de la llamada "controversia monetarista" (Laidler 1990), como una alternativa a los modelos keynesianos, que fueron dominantes en macroeconomía desde los años treinta (Johnson 1971). En los cincuenta, Friedman (1956, 1961a) presentó la tesis de que el dinero era importante y de que su demanda era una función estable de unas pocas variables (Laidler 1993). Las primeras escaramuzas de la controversia se centraron en la evidencia empírica sobre esa función (Friedman 1966a), pero se extendieron pronto al impacto de los impulsos monetarios sobre variables reales y precios, la existencia de un intercambio a largo plazo entre inflación y desempleo, el mecanismo de transmisión de la política monetaria, la endogeneidad y controlabilidad de la oferta de dinero y la idoneidad de los modelos IS-LM (Brunner 1968; cfr. Argandoña 1981, caps. 10 y 11). El auge del monetarismo como escuela tuvo lugar en los años setenta, debido a tres factores:

1. La acentuación de los problemas macroeconómicos —alta inflación, shocks de oferta, estanflación, inestabilidad de la relación entre inflación y desempleo) - que los monetaristas habían anunciado.

2. La incapacidad de los modelos vigentes para dar cuenta de esos problemas, y de las políticas keynesianas para ofrecer soluciones eficaces. La lista incluye el repetido fracaso de los controles de precios y salarios (Friedman 1966b); el esfuerzo infructuoso por mantener bajos los tipos de interés, a fin de facilitar la financiación del déficit público, y el recurso a políticas de stop and go, que desembocaron en sucesivos episodios de inflación y recesión. En esos años las autoridades monetarias aplicaron "una combinación de instinto, juicio y corazonadas crudas para evaluar las implicaciones de las diferentes trayectorias de política sobre la economía" (Galí y Gertler 2007, 25-26), de modo que puede afirmarse que "al menos durante la década de 1970, la banca central se encontraba en un estado de profunda confusión intelectual" (Hall y Sargent 2018, 133).

3. Ante la necesidad de una renovación conceptual y práctica, el monetarismo ofrecía un marco teórico novedoso, apoyado en evidencias empíricas. Además, "los años anteriores a 1981 constituyeron un periodo extraordinario para confirmar las hipótesis monetaristas" (Hetzel 2017, 7): la demanda de dinero fue estable y los agregados monetarios mostraron una relación estable con el producto nominal.

"Los efectos del discurso presidencial de Friedman (1968a) sobre las variables macroeconómicas operaron principalmente a través de los bancos centrales" (Hall y Sargent 2018, 133), inspirando una nueva política monetaria. El 6 de agosto de 1979, James Carter nombró a Paul Volcker presidente de la Reserva Federal (la Fed), con el encargo explícito de frenar la inflación. Dos meses después, la Fed anunció un cambio profundo en su operativa, orientada ahora a manejar el crecimiento de la cantidad de dinero mediante el control de un agregado monetario: las reservas bancarias menos el crédito de la Fed a los bancos (McCallum 2008). El resultado fue una rápida caída de la tasa de inflación, aunque con tipos de interés muy altos y volátiles y una recesión severa. También Margaret Thatcher aplicó en el Reino Unido una política de contención monetaria que redujo la inflación, asimismo con el coste de un alto desempleo. Y se puede hablar también del monetarismo en la práctica del Bundesbank de controlar el crecimiento de un agregado monetario, que influyó en el diseño del Banco Central Europeo (Mayer y Minford 2004).

La opinión pública calificó a estas políticas de monetaristas, y esto contribuyó a dar a conocer la escuela, aunque tanto Brunner (1983) como Friedman (1984) negaron que la estrategia de Volcker estuviese de acuerdo con los criterios que ellos habías sugerido: una tasa de crecimiento estable, predecible y anunciada del agregado monetario objetivo, un calendario comprometido y el control de la base monetaria.

En todo caso, los siguientes años fueron adversos para las tesis monetaristas. La demanda de dinero se

\footnotetext{
Parece que muchas de las convicciones de Friedman sobre el dinero y la política monetaria se basan en su trabajo con Anna Schwartz (Friedman y Schwartz 1963a).
} 
volvió muy volátil (B.M. Friedman 1997), debido a la reforma de la Regulación Q, que abrió la posibilidad de ofrecer cuentas corrientes con interés, y a otras innovaciones que dieron lugar a desplazamientos de activos hacia agregados amplios, no solo en Estados Unidos, sino también en Canadá, Reino Unido, Australia y Nueva Zelanda, dificultando el control de la cantidad de dinero.

Pocos años después, "a principios de los años ochenta la controversia monetarista se dio por superada, y el monetarismo [quedó] desacreditado a los ojos de la mayoría de observadores" (Laidler 1990, 59-60): a partir de 1982 la Reserva Federal puso fin al experimento monetarista. Pero "el pensamiento de Friedman (...) había puesto en marcha un proceso educativo muy exitoso, que llevó a la mayoría de los bancos centrales del mundo a abandonar las políticas de alta inflación y comprometerse con políticas eficaces de estabilización" (Hall y Sargent 2018, 133). Los años de la Gran Moderación, desde 1985 hasta mediados de la década de los 2000, pusieron de manifiesto que las políticas de inspiración monetarista podían conseguir estabilidad financiera, inflación baja, crecimiento sostenido, desempleo reducido y recesiones suaves y breves (De Long 2000, 80).

\section{Las tesis monetaristas}

\subsection{La estabilidad de la economía}

En las primeras generaciones de modelos keynesianos IS-LM con precios fijos (Hicks 1937), el mecanismo de transmisión era un (único) tipo de interés, que influía en las decisiones de consumo e inversión y en la colocación de la riqueza entre dos activos, dinero y bonos ${ }^{5}$. Las perturbaciones se producían por insuficiencia de la demanda agregada, es decir, por excesos de ahorro o volatilidad de la inversión (los animal spirits), o porque la economía caía en una trampa de la liquidez. Se suponía que los precios venían fijados institucionalmente por los grandes monopolios (Hetzel 2007, 12) o por aumentos exógenos de los salarios; los ajustes tenían lugar a través de cantidades, no de precios: de ahí la inevitabilidad del equilibrio con desempleo, si no se corregía con la política fiscal (Friedman 1974, 16 y ss.).

Por el contrario, los monetaristas sostenían que el sector privado es estable: los mercados libres funcionan razonablemente bien. Si los precios y salarios son flexibles, el producto real se mantendrá próximo al nivel de pleno empleo, de modo que no será necesaria una política fiscal activista, tanto en las pequeñas desviaciones alrededor del equilibrio como en grandes perturbaciones, como la Gran Depresión (Brunner 1983, 27).

\subsection{El dinero y la teoría cuantitativa}

El fundamento teórico del monetarismo es la teoría cuantitativa del dinero (Fisher 1920; Friedman 1956, 1968b; cf. Argandoña 1981, cap. 1). Su origen es la ecuación de cambios, M.V = P.Y, una identidad que establece que la cantidad de dinero, $\mathrm{M}$, multiplicada por la velocidad de circulación del dinero, $\mathrm{V}$, es igual al producto nominal, es decir, al producto real, Y (o al volumen de transacciones), multiplicado por el nivel de precios, $\mathrm{P}$.

Si la velocidad $\longrightarrow$ o su inversa, la demanda de dinero- es constante o, al menos, una función estable de unas pocas variables (Friedman 1956; 1959; Selden 1956), la ecuación de cambios se convierte en la teoría cuantitativa: los cambios en la cantidad de dinero determinan los del producto nominal. La evidencia empírica apoyaba el supuesto de estabilidad de la demanda de dinero (Meltzer 1963), incluso durante una hiperinflación (Cagan 1956).

Esto implica que la cantidad de dinero es el principal determinante de las fluctuaciones económicas y que el nivel de precios se mueve de acuerdo con los cambios en la cantidad de dinero, porque "no hay quizás una regularidad empírica entre los fenómenos económicos que se base en tanta evidencia para una tan amplia gama de circunstancias como la conexión entre cambios sustanciales en la cantidad de dinero y en el nivel de precios" (Friedman 1958, 172) $)^{6}$ : "la inflación es siempre y en todas partes un fenómeno monetario" (Friedman 1963, 39; 1983, 46).

En el monetarismo el dinero no es solo el conjunto de activos usados como medio de pago, sino también un artefacto social que reduce los costes de información y de transacción (Brunner y Meltzer 1971): “al usar el dinero los individuos reducen la cantidad de información que deben adquirir, procesar y almacenar, así como el número de transacciones que deben llevar a cabo para intercambiar su dotación inicial de recursos por su cesta óptima de bienes" (Brunner y Meltzer 1971, 799; cfr. Brunner 1983, 29). O sea: los monetaristas entienden al agente económico como racional, con visión de futuro, que busca y maneja la información que necesita. Y los costes de conseguir, almacenar y emplear esa información van a tener mucha relevancia en su teoría (Brunner y Meltzer 1972a).

\subsection{Neutralidad del dinero}

Si la demanda de dinero es estable y el producto fluctúa alrededor del nivel de pleno empleo, el dinero debe ser neutral a largo plazo, es decir, no influye en el producto potencial, en el real o en el empleo. Ese plazo no es un periodo determinado, sino el tiempo

Bordo y Schwartz (2004) analizan la evolución de las sucesivas generaciones de modelos IS-LM.

6 Friedman y Meiselman (1963) mostraron que las correlaciones entre dinero y consumo eran mayores que las que había entre consumo y el gasto autónomo; cfr. también Andersen y Jordan (1968). 
(variable) en que los agentes recogen y procesan la información y adaptan sus expectativas?

A corto plazo el dinero no es neutral. Una expansión monetaria aumentará las tenencias de dinero y quizás también la riqueza nominal de algunos agentes; si la demanda de dinero es estable, ese dinero será gastado, aumentando el consumo y el producto real y, tras un tiempo, los precios, hasta volver a una situación de equilibrio, con el mismo producto real, precios más altos y la misma cantidad real de dinero. Para los monetaristas, esa no neutralidad a corto plazo se debe a la información imperfecta que los agentes tienen sobre la causa y la persistencia de los shocks y el mecanismo de propagación de sus efectos (Meltzer 1995, 49-50).

\subsection{El intercambio entre inflación y empleo}

La limitación de precios fijos en los modelos keynesianos IS-LM se resolvió añadiendo una curva de Phillips (1958), que establece una relación entre variables reales - el producto real, la brecha del producto potencial, el empleo o el desempleo, o sus tasas de variación - y nominales - el nivel o la tasa de variación de los precios o salarios nominales-. Con base en esta relación, Samuelson y Solow (1960) ofrecían a los gobiernos la posibilidad de elegir entre políticas que producían menos desempleo con más inflación o viceversa.

Friedman (1968a) mostró que, a largo plazo, no existe ese intercambio entre empleo e inflación ${ }^{8}$ : una política monetaria expansiva aumenta la demanda y reduce el desempleo a corto plazo, pero cuando los precios crecen, o mejor, cuando los agentes revisan al alza sus expectativas de inflación, el efecto expansivo desaparece, si los precios son suficientemente flexibles. A largo plazo, la curva de Phillips es una vertical al nivel de la tasa natural de desempleo, que Friedman (1968a, 8) definió como un "nivel que vendría determinado por el sistema walrasiano de ecuaciones de equilibrio general, siempre y cuando lleven incorporadas las características estructurales reales de los mercados laborales y de productos básicos, incluidas las imperfecciones del mercado, la variabilidad estocástica de las demandas y las ofertas, el coste de recoger información sobre vacantes laborales y disponibilidad de la mano de obra, los costes de la movilidad, etc." O sea, "muchas de las características del mercado que determinan el nivel [de la tasa natural de desempleo] son provocadas por las personas y por las políticas" (Friedman 1968a, 9; cfr. Brunner 1983, 28).

\subsection{Tipos de interés nominales y reales}

Los monetaristas incorporaron a su análisis la distinción entre tipos de interés nominales y reales (Fisher 1930). Para los keynesianos, esta distinción no era relevante: un tipo de interés nominal bajo era siempre un indicador de expansión monetaria.

Fisher explicó también que un aumento de la tasa de crecimiento de la cantidad de dinero da lugar a tres efectos sobre los tipos de interés: efecto liquidez - una reducción del tipo real, que impulsa la demanda y el producto a corto plazo-, efecto renta - un aumento posterior del tipo real debido al aumento del producto, volviendo al nivel de partida - y efecto Fisher, por el que el tipo de interés nominal incorpora la expectativa de una inflación más alta. Por tanto, para un monetarista un tipo de interés nominal alto podía significar una economía en expansión - tipos reales altos - o mayores expectativas de inflación, de modo que los tipos nominales no son un indicador fiable de la situación de la economía, y la política monetaria no puede lograr su estabilidad.

\subsection{Las expectativas}

Agentes racionales que deciden mirando hacia el futuro y usan adecuadamente la información disponible actúan de acuerdo no con los valores pasados o presentes de las variables, sino con sus expectativas de futuro 9 . Al principio, los modelos incorporaban las expectativas de manera adaptativa: por ejemplo, ante un aumento del nivel de precios se consideraba que los agentes tomaban una parte de ese aumento como permanente y otra como transitoria, y que esta última desaparecería o se revertiría, de modo que las expectativas de inflación se adaptarían a lo largo del tiempo; solo en el largo plazo las expectativas incorporarían toda la información contenida en las variables y, en ausencia de nuevas perturbaciones, el valor efectivo y el esperado se igualarían.

\subsection{El mecanismo de transmisión}

Una parte importante de la controversia monetarista tuvo lugar alrededor del mecanismo de transmisión de los impulsos o perturbaciones: cambios en variables exógenas, como la tecnología, las preferencias o la cantidad de dinero ${ }^{10}$ (Brunner y Meltzer 1972a,b; 1973). En los modelos keynesianos de los años sesenta el mecanismo de transmisión era uno solo, el intercambio entre dinero y bonos: más dinero lleva a la compra de bonos, cuyo precio aumenta y cuyo

La neutralidad es una hipótesis relacionada con la conducta racional de los agentes (Meltzer 1995, 49) y no depende de cómo se gestione la política monetaria.

Phelps (1967) llegó independientemente a la misma conclusión.

9 La formación de las expectativas está relacionada con la distinción entre componentes permanentes y transitorios introducida en la teoría de la renta permanente de Friedman (1957).

10 El impulso monetario tiene un componente tendencial, que es el que domina en la tasa de inflación, y un componente estocástico, dado por las perturbaciones no anticipadas y erróneamente percibidas, que influye en las fluctuaciones del producto a corto plazo (Brunner 1983, 29). 
rendimiento - el tipo de interés - se reduce, lo que incide sobre el gasto.

El mecanismo de transmisión monetarista opera a través de cambios en el volumen y la composición de la riqueza, modificando los precios relativos e iniciando un proceso de sustitución que se extiende por todos los mercados de valores, crédito y producción (Brunner y Meltzer 1976; Friedman y Schwartz 1963b; Meltzer 2001). Por ejemplo, un aumento del efectivo en manos del público produce un efecto riqueza, que se transmite a los depósitos en los bancos, cuyas reservas libres aumentan; los bancos reducen el tipo de interés de los créditos, que es el mismo mecanismo keynesiano sobre el consumo y la inversión, pero ahora ampliado a las compras de otros activos financieros (acciones) y reales (inmuebles), alterando sus rendimientos relativos; estos efectos se prolongarán a lo largo del tiempo en toda la economía (cf. Argandoña 1981, 369-371).

El monetarismo amplía, pues, la gama de activos y de tipos de interés implicados en el mecanismo de transmisión, además de los efectos riqueza que operan a través del balance de los agentes privados y de los bancos. La demanda de dinero a corto plazo "refleja las complejas interacciones de la cantidad de dinero con otras variables [también institucionales, legales y culturales] a las que se referían los monetaristas (...) como un mecanismo de transmisión sujeto a retardos largos y variables" (Laidler 1990, 62) ${ }^{11}$.

\subsection{La política monetaria}

\subsubsection{El marco institucional y operativo}

Los monetaristas ejercieron una profunda influencia en la concepción moderna de un banco central, empezando por su marco institucional que, en una democracia, tiene componentes constitucionales, legales e institucionales - estado de derecho, libre iniciativa, derechos de propiedad, mercado, sistema judicial, etc. - Se apoya fundamentalmente en tres pilares: 1) un mandato que dé prioridad a la estabilidad de precios; 2) independencia política, administrativa y presupuestaria del banco central, especialmente en el procedimiento para nombrar sus altos cargos y su duración (Cukierman 1992), y 3); rendición de cuentas, que hace más eficaz la credibilidad y la transparencia, incentiva el cumplimiento del mandato y facilita el control democrático. Estas condiciones, que hoy en día cumplen con más o menos profundidad los principales bancos centrales del mundo, les otorgan un gran poder que, como veremos, los monetaristas querían que se usase de manera prudente.

El marco operativo de la política monetaria que se fue desarrollando en esos años incluía cuatro niveles de actuación (Brunner y Meltzer 1969; B.M. Friedman 1976): 1) objetivos últimos: estabilidad de precios, pleno empleo, crecimiento, estabilidad cambiaria, etc.; 2) objetivos intermedios - agregados monetarios amplios o tipos de interés - medibles, controlables y con efectos predecibles sobre los objetivos últimos; 3 ) indicadores u objetivos operativos: la base monetaria o un tipo de interés a corto plazo; y 4) instrumentos - operaciones de mercado abierto, coeficiente de reservas, ventanilla de descuento, etc.- directamente controlables por el banco central.

La posición monetarista sobre esos niveles de actuación era la siguiente:

1. Si la estabilidad financiera es clave para la prosperidad económica de un país y si el nivel de precios es la variable que conduce al equilibrio económico, el objetivo de la política monetaria debe ser el control de la inflación, definido como una tasa baja y estable que se alcanza de modo tendencial, a largo plazo; no se deben incluir objetivos en variables reales: producción, empleo, etc. La política monetaria podía usarse también para compensar perturbaciones graves procedentes de otras causas, aunque sin demasiada confianza, porque "no sabemos lo suficiente como para poder reconocer perturbaciones menores cuando ocurren o para predecir cuáles serán sus efectos con precisión, o qué política monetaria se requiere para compensar sus efectos" (Friedman 1968a, 14).

2. A corto plazo, la tasa de inflación experimenta variaciones respecto de la tendencia marcada por el crecimiento de la cantidad de dinero. Por eso, hace falta un objetivo intermedio que permita a las autoridades monetarias comprobar que están en línea con la consecución de su objetivo último, a pesar de esas desviaciones. Los monetaristas se inclinaban por utilizar como objetivo intermedio un agregado monetario amplio, aquel que tuviese una relación estadística más clara con la inflación ${ }^{12}$.

3. El indicador debe ser un agregado, la base monetaria, pero no un tipo de interés.

4. Cada banco central debe encontrar los instrumentos que mejor se acomoden a la estructura institucional y legal del país.

\subsubsection{Objetivos y reglas}

"Estas son las principales lecciones de Friedman: que la política monetaria es importante, que es importante para la estabilidad financiera, que la estabilidad

\footnotetext{
En la reciente crisis financiera se ha puesto de manifiesto que en las relaciones entre instituciones financieras y mercados juegan los cambios no solo en precios relativos y rendimientos, sino también en riesgos e información.

12 En esto se movían por razones tácticas, no estratégicas, porque sus estimaciones empíricas con agregados monetarios daban mejores resultados y, sobre todo, por la mala experiencia en el uso de un tipo de interés como indicador de la política monetaria en las décadas anteriores (Schwartz 2008, 260).
} 
financiera es importante para la prosperidad económica y que la transmisión de la política monetaria se produce principalmente a través de lo que ahora llamamos canales de balance, en lugar de canales de gasto" (Du Plessis 2014, 10). El objetivo de la política monetaria no debe ser cerrar una brecha entre el producto potencial y real, sino estabilizar una trayectoria de dinero y precios (De Long 2000, 84).

Los monetaristas deseaban un banco central poderoso y libre de influencias políticas, pero temían que se propusiese llevar a cabo políticas activistas que, tratando de conseguir resultados a corto plazo, causasen inestabilidad. Por ello proponían seguir una regla óptima y robusta ante los posibles errores de comprensión de la estructura de la economía y de implementación de las políticas (Friedman 1960).

Las razones que abonan este planteamiento son varias: 1) la política monetaria opera con retardos "largos y variables" (Friedman 1961b, 464), de modo que los efectos de una decisión discrecional se producirán cuando algunas variables ya habrán cambiado, con lo que esa política puede ser perturbadora. 2) Una estrategia discrecional de decisiones desconectadas entre sí puede ser temporalmente inconsistente (cfr. Kydland y Prescott 1977). 3) Practicando una regla estable y sencilla, las reacciones de los agentes privados serán compatibles con las del banco central. 4) Una política activista exige conocer de manera detallada y fiable la estructura determinista y estocástica de la economía, algo que los monetaristas niegan, porque "la naturaleza de los procesos económicos (...) modifica continuamente el capital de información" (Brunner 1983, 32). 5) Las reglas evitan el riesgo de presiones políticas a corto plazo y facilitan la rendición de cuentas ${ }^{13}$.

Las propuestas de los monetaristas acerca de las reglas monetarias concretas fueron cambiando con el tiempo, de un crecimiento constante de la cantidad de dinero que asegurase una tasa de inflación nula o muy reducida (Friedman 1960), a alguna regla de crecimiento de un agregado monetario con feedback (Brunner y Meltzer 1993, McCallum 1984, Meltzer 1987) o a una regla de deflación que hiciese nulo el tipo de interés real (Friedman 1969). En todo caso, lo distintivo del monetarismo no es el seguimiento de una regla monetaria, sino lo que se pretende con esa política: conseguir una tasa de inflación baja, estable y predecible, y someter al banco central a un patrón de conducta que impida la manipulación política de sus actuaciones ${ }^{14}$.

\subsection{Los modelos monetaristas}

Avanzada ya la controversia monetarista, sus críticos, keynesianos o no, argumentaron que carecían de un modelo teórico sólido y bien formado (Bordo y Schwartz 2004, 231). Por eso, Friedman (1970; 1971) decidió elaborar modelos teóricos basados en la teoría cuantitativa, aunque compatibles con los modelos IS-LM ${ }^{15}$, pero no convencieron ni a sus críticos, ni a otros monetaristas. Por ejemplo, Brunner y Meltzer (1972a) publicaron un detallado análisis de los modelos friedmanianos, señalando algunas de sus limitaciones: la rigidez de la oferta, al suponer que el producto estaba siempre en pleno empleo y no incluir una función de producción; la conveniencia de incorporar costes de ajuste y de búsqueda de información; la necesidad de explicitar las vías por las cuales aumenta la cantidad de dinero; introducir una variedad de mercados de activos y variables fiscales; explicar las opciones abiertas el público por la compra y venta de activos; introducir los efectos de feed-back de los tipos de interés, la renta real y la riqueza sobre la oferta de dinero, etc.

Brunner y Meltzer también elaboraron modelos alternativos al IS-LM (Brunner 1970; 1974; Brunner y Meltzer 1972b,c; 1973; 1976; 1993), que incorporaban un mercado de crédito, con tres activos que eran sustitutivos imperfectos: base monetaria, deuda del gobierno y capital real; completaban el modelo ecuaciones sobre la demanda y la oferta agregadas, la restricción presupuestaria del gobierno y las condiciones de equilibrio de los distintos mercados. En todo caso, los modelos monetaristas no consiguieron la aprobación de los macroeconomistas, aunque algunos de sus elementos pasaron a formar parte de la economía convencional, como veremos más adelante.

\section{Teorías y políticas post-monetaristas}

Desde la conferencia de Friedman como presidente de la American Economic Association (1968a) ha pasado medio siglo, y han tenido lugar muchos acontecimientos, incluyendo una grave crisis financiera y la Gran Recesión. ¿Qué ha cambiado en la teoría y la política monetaria? En lo que sigue, revisaremos algunas de las concepciones teóricas y de política que están vigente hoy en día, muchas de las cuales están relacionadas con las propuestas monetaristas. Esta sección es, pues, un ejercicio - muy limitado- de interpretación de la influencia de la política y la teo-

\footnotetext{
Frente a los que afirman que no es conveniente que las autoridades monetarias se aten las manos ante sucesos futuros, los monetaristas defienden la importancia de que las expectativas de los agentes estén alineadas con las acciones del banco central (Friedman 1962). Las acciones extraordinarias, como una actuación enérgica ante una crisis financiera, pueden formar parte también de una regla y del consiguiente compromiso del banco central (Meltzer 1998, 12). Sobre los modelos con reglas, cf. Argandoña (1996), cap. 6.

14 Los monetaristas no apoyaron el patrón oro (Brunner 1983) que, si bien aislaba la política monetaria de las presiones políticas, no garantizaba la estabilidad financiera (Dellas y Tavlas 2018). Asimismo, Friedman (1953b) defendió los tipos de cambio flexibles, que permiten la gestión descentralizada de la política monetaria a nivel nacional y aíslan la economía de las perturbaciones exteriores.

15 Más tarde, Friedman (2001) reconoció que tratar de reconciliar el pensamiento keynesiano con el monetarista fue una pérdida de tiempo.
} 
ría monetaristas, y no pretende ser un examen de su evolución en los últimos decenios.

\subsection{La política monetaria post-monetarista}

La concepción actual de la política monetaria contiene numerosos elementos monetaristas. Por ejemplo, hoy se admite que esa política es efectiva para controlar la inflación en el largo plazo y también en el corto, en que el dinero no es neutral, pero siempre dentro de la tendencia que marca la neutralidad a largo plazo. Se acepta, pues, una curva de Phillips, pero como función de oferta agregada, no como determinante o descriptor de la inflación: las empresas y familias configuran los precios relativos, pero el nivel de precios depende del áncora nominal establecida por la política monetaria, no en términos de una tasa de crecimiento de la cantidad de dinero - los agregados monetarios no tienen en la actualidad un papel relevante - sino del ancla que establece el banco central con su compromiso de conseguir una tasa de inflación tendencial, a medio plazo.

\subsubsection{Objetivos y reglas}

El marco de actuación de la política monetaria se elabora hoy en tres niveles: objetivos, instrumentos e indicadores; los objetivos intermedios que proponían los monetaristas han caído en desuso, porque su relación con los instrumentos depende de factores institucionales, que no son constantes en el tiempo ni en el espacio ${ }^{16}$.

En la actualidad hay un amplio consenso en que el objetivo último de la política monetaria debe ser crear y mantener un marco financiero estable. Los principales bancos centrales han optado por un objetivo en términos de una tasa de inflación cuantificada, baja, estable, anunciada y, por tanto, predecible. "La creencia de que, a largo plazo, el banco central puede hacer poco sobre las variables reales sigue siendo canon para la mayoría de los macroeconomistas, y pocos sugerirían que la política monetaria debería incluir objetivos sobre la participación en la fuerza laboral, la desigualdad o la tasa de interés real a largo plazo" (Mankiw y Reis 2018, 89). Pero la crisis financiera ha puesto de manifiesto que no basta la estabilidad en términos de precios de bienes de consumo, sino que están implicadas también los precios de los activos (burbujas), la difusión de riesgos, los fenómenos de contagio y las operaciones que tienen lugar fuera del sistema bancario estricto, aspectos estos que ya aparecían en los modelos monetaristas.

Como había propuesto Friedman (1968a), hoy se admite que la política monetaria puede llevar a cabo actuaciones extraordinarias, como se puso de manifiesto en la crisis financiera, cuando "la Reserva Federal y muchos otros bancos centrales respondieron agresivamente. Al evitar quiebras bancarias, proporcionar crédito de emergencia a los intermediarios financieros y aumentar las reservas bancarias, el banco central se aseguró de que la oferta monetaria (...) no cayera tan precipitadamente como lo hizo durante la Gran Depresión; Friedman lo habría aprobado" (Mankiw y Reis 2018, 91) ${ }^{17}$.

En la actualidad hay un amplio consenso en que la política monetaria no debe ser discrecional, sino seguir reglas, que deben ser flexibles en la estimación de la situación y en la ejecución de la regla, puesto que una respuesta automática y brusca a las desviaciones de la tasa de inflación respecto de su objetivo puede ser desestabilizadora; esas reglas deben ser transparentes, sencillas y comprensibles para el público, robustas (Friedman 1960), no deben incorporar percepciones o interpretaciones sobre variables futuras, que podrían dar lugar a interferencias políticas, $\mathrm{y}$ deben ir acompañadas de un compromiso firme y creíble para su aplicación -pero compromiso con el objetivo, no con la regla (Galí 2018).

Los bancos centrales prefieren reglas adaptativas, como alguna variante de la regla de Taylor (1993), que combina la corrección de las desviaciones de la tasa de inflación respecto de su objetivo con la corrección de las desviaciones de la tasa de crecimiento del PIB real respecto del potencial. Estas reglas permiten ajustar el tipo de interés nominal más que proporcionalmente a la inflación esperada, de modo que, si la inflación crece, el tipo de interés real aumenta y la demanda agregada se reduce para volver al equilibrio, lo que permite compensar los shocks de demanda y acomodar los de oferta, como corresponde a una regla óptima (Theil 1964). Una ventaja de tales reglas es que el banco central no tiene que perseguir dos objetivos, inflación y brecha del producto potencial, porque, bajo ciertas condiciones, se produce la "divina coincidencia" (Blanchard y Galí 2007): basta que la política monetaria trate de conseguir una inflación estable y creíble para que, automáticamente, se estabilicen el producto y el empleo en niveles próximos a su potencial. Para anticiparse a los retardos de la política monetaria, los bancos centrales han adoptado objetivos de inflación esperada o pronosticada (Woodford 2007).

Lo dicho acerca de los objetivos y las reglas exige que el banco central comunique claramente sus objetivos, debidamente cuantificados; explique los análisis que los fundamentan, las variables que observa y cómo las interpreta, y mantenga las reglas, cambiándolas solo cuando sea muy necesario y explicando

\footnotetext{
16 Los bancos centrales "han seguido utilizando gran cantidad de discreción para inferir el estado de la economía a partir de muchas medidas imperfectas y para reaccionar ante la gran variedad de shocks (...) [y han puesto] un gran énfasis en la transparencia de las acciones del banco central" (Mankiw y Reis 2018, 90).

17 Pero la disposición de los bancos centrales a actuar inmediatamente contra cualquier caída importante de la actividad económica y de la bolsa, inyectando liquidez y poniendo un límite a la pérdida que pueden sufrir los inversores (el llamado Greenspan put) puede crear riesgo moral, lo que, probablemente, no merecería la aprobación de los monetaristas.
} 
por qué lo hace y qué espera de esos cambios. La credibilidad de la política monetaria se apoya en una política de comunicación transparente, en la imagen de honestidad de sus gestores, en la independencia del banco central y, naturalmente, en la consistencia de su política y de su puesta en práctica.

\subsubsection{Los instrumentos}

El instrumento preferido por los bancos centrales es hoy un tipo de interés, bajo el supuesto de que los efectos de la política monetaria se transmiten no a través de agregados monetarios, como proponían los monetaristas, sino de sus precios, o sea, de los tipos de interés, y que los tipos de diversos mercados y vencimientos están conectados entre sí y con los tipos de interés que controla el banco central (hipótesis de las expectativas) ${ }^{18}$.

El manejo de los tipos de interés se lleva a cabo a través del precio y del volumen de las reservas (depósitos de los bancos en el banco central), que "son en la actualidad uno de los mayores activos financieros homogéneos, y [que] el banco central puede controlar de forma independiente (...). El 'reservismo' puede convertirse en la nueva cara del monetarismo, no como un objetivo de política, sino como un enfoque de la inflación y como una guía para los bancos centrales para sus políticas de 'flexibilización cuantitativa' y otros usos del balance del banco central" (Mankiw y Reis 2018).

\subsubsection{La política monetaria en la crisis financiera}

La crisis financiera que se inició en 2007 obligó a los bancos centrales a utilizar a fondo los instrumentos de que disponían y a ampliar su gama. No es este el lugar para explicar las causas y caracteres de esa crisis y de la Gran Recesión que la siguió ${ }^{19}$, pero conviene señalar que las respuestas de los bancos centrales tuvieron mucho que ver con algunas posiciones monetaristas.

Desde el comienzo de la crisis, los bancos centrales ampliaron el alcance de su política de provisión de liquidez, reduciendo sus tipos de interés, ampliando los plazos y las garantías admitidas y extendiéndolas a otras entidades; de este modo trataban de evitar los pánicos bancarios y facilitar el crédito al sector privado. De alguna manera, estas medidas, que suelen concebirse como transitorias, se convirtieron en permanentes, cuando se alargó el bloqueo de los mercados, la inestabilidad de las instituciones financieras, la contracción del crédito ${ }^{20}$, las dudas sobre sostenibilidad de la deuda pública — especialmente en Europa-, la caída del tipo de interés natural y, más recientemente, las dificultades para recuperar el crecimiento económico (hipótesis del estancamiento secular: Summers 2014) y para volver a niveles de inflación compatibles con los objetivos nacionales (Schwartzer 2018, 207).

Las autoridades monetarias se enfrentaron también a dificultades para reducir los tipos de interés cuando estos llegaron al límite inferior efectivo (effective lower bound, ELB, o zero lower bound, ZLB), recurriendo para ello a medidas de flexibilización cuantitativa (quantitative easing, $\mathrm{QE}$ ) y de orientación hacia adelante (forward guidance, FG). Estas medidas formaban parte, de un modo u otro, de la caja de herramientas monetarista ${ }^{21}$.

Las medidas de QE alteran los balances de los bancos y del público, cambiando los precios relativos de los activos y sus rentabilidades, es decir, un amplio conjunto de tipos de interés, nominales - a través de las expectativas de inflación - y reales - alterando las primas de riesgo y de liquidez - para diversos plazos y activos (Blinder 2013, Eggertsson y Woodford 2003, Mankiw y Reis 2018), de acuerdo con los mecanismos monetaristas de transmisión (Meltzer 2004, 163). Pero el impacto de esas medidas puede ir más allá de la mera alteración de las primas de riesgo y liquidez, y del cambio en la estructura temporal de los tipos de interés, si se trata de operaciones no esterilizadas, es decir, que aumentan la base monetaria, como contemplaban los monetaristas, de modo que se producen también efectos cuantitativos en el balance de las entidades financieras y del público en general.

Las acciones de forward guidance son intervenciones indirectas dirigidas a influir en los tipos de interés de plazos medios y largos, con objeto de ofrecer seguridades de que la política iniciada a corto plazo tendrá una larga duración, que se trasladará a los tipos a plazos largos. Como ya explicamos, el mecanismo de transmisión monetarista contempla una amplia gama de activos y tipos de interés, incluyendo los costes de adquisición de información - claves en las operaciones de forward guidance - , la formación de las experiencias y expectativas de los agentes y la variedad de riesgos - no solo de un activo, sino de contagio entre activos y entidades, incluyendo los riesgos sistémicos-.

\subsection{El post-monetarismo en la teoría macroeco- nómica}

En los años que van desde la decadencia del monetarismo hasta la crisis financiera y la Gran Recesión se

18 Después de la crisis financiera, los bancos centrales intervienen no solo en el extremo corto de la curva de rendimientos, sino sobre toda ella.

19 Cf. Blinder (2013). Una explicación plausible del origen de la Gran Recesión, basada en el abandono del control de la cantidad de dinero por el Banco Central Europeo a partir de 2003, es la de Castañeda y Congdon (2017).

20 En algunos momentos, los bancos centrales tuvieron que cortocircuitar la intermediación bancaria para proporcionar directamente crédito al sector privado.

21 Los monetaristas ofrecieron también algunas explicaciones anticipadas y útiles acerca de la naturaleza y alcance de la crisis financiera. Por ejemplo, el cierre de los mercados y las dificultades de financiación de los bancos aumentaron la productividad marginal de las reservas, lo que redujo los multiplicadores monetarios; los tipos de interés aumentaron y se redujo el valor de los activos, lo que contrajo más el crédito bancario (Brunner y Meltzer 1988, 447-448). 
han producido numerosas innovaciones teóricas, que no es posible explicar aquí con detalle. En esta sección mencionaremos algunas de ellas, de manera necesariamente incompleta y poco ordenada, en lo que tienen de relación con el pensamiento monetarista.

\subsubsection{Expectativas racionales y nueva economía clásica}

Uno de los temas que ocuparon la atención de los macroeconomistas en los años setenta fue la hipótesis de las expectativas racionales (Lucas 1972, 1973; Sargent y Wallace 1975; cf. Argandoña 1981, cap. 12): si los agentes son racionales y usan eficientemente la información, sus expectativas seguirán el mismo proceso de formación que el modelo que las explica; esto daba un mayor grado de coherencia a los modelos e introducía un cambio importante en la manera de enfocar la eficacia de la política monetaria, porque reducía la no neutralidad del dinero a la existencia de "sorpresas" monetarias, siempre que los precios y salarios sean flexibles y se ajusten inmediatamente (Argandoña et al. 1996, cap. 7).

Muchos monetaristas vieron con simpatía la hipótesis de las expectativas racionales, porque acentuaba el carácter racional de la toma de decisiones, mejoraba la calidad dinámica de los modelos y confirmaba algunas de sus hipótesis sobre el papel del dinero. Pero otros hicieron notar que, cuando se tienen en cuenta los costes de recibir y procesar la información, el ajuste de precios no puede ser instantáneo, aun con expectativas racionales (Brunner y Meltzer 1993).

Una derivación importante de la hipótesis de racionalidad de las expectativas fue la crítica de Lucas (1976): si los agentes forman sus expectativas con la información disponible, y esta se extiende también a los propósitos de las autoridades monetarias, un cambio en la política cambiará las reacciones de los agentes y los parámetros del modelo, de modo que la estimación de los posibles efectos de aquel cambio de política será errónea. Para evitar esta crítica, los modelos deben apoyarse en microfundamentos coherentes (Lucas y Sargent 1978).

Todo esto se concretó en la Nueva Economía Clásica que, a los ojos de muchos, parecía la continuación de las tesis monetaristas ${ }^{22}$. Pero se separaba de ellas en puntos importantes, como el mecanismo de transmisión, el retraso de acción de la política monetaria, la flexibilidad de los precios y el ajuste lento de las carteras, fruto de las deficiencias de la información. Pero, sobre todo, se separaba de las prioridades metodológicas del monetarismo, al otorgar mayor importancia a los microfundamentos teóricos que a la evidencia empírica. Por eso fue rechazada por las figuras destacadas del monetarismo, como Friedman y Brunner; este, por ejemplo, calificaba de "parodia de la ciencia" a la imposición metodológica de que todo razonamiento económico debe comenzar desde los "primeros principios" (Brunner 1984, 16; 1989, 195; cf. también Wren-Lewis 2018) ${ }^{23}$.

Un componente importante de la Nueva Economía Clásica fue la Teoría de los Ciclos Reales, basada en versiones estocásticas de los modelos neoclásicos de crecimiento de Meade y Solow y Swan (cfr. Prescott 1986). En una economía competitiva en que los mercados funcionan eficientemente, las fluctuaciones cíclicas se deberán a perturbaciones en la función agregada de producción, y el papel del dinero pasa a ser pasivo, de acuerdo con la tesis keynesiana de que los cambios en el dinero son resultado de los cambios en la renta (King y Plosser 1984), lo contrario de lo que proponían los monetaristas.

\subsubsection{La Nueva Economía Keynesiana y la Nueva Síntesis Neoclásica}

A partir principalmente de las críticas de los Nuevos Clásicos, la Nueva Economía Keynesiana (Gordon 1990; Mankiw y Romer 1991) ha tratado de desarrollar desde los años setenta las ideas keynesianas a partir de modelos de equilibrio general, introduciendo microfundamentos sólidos y agentes optimizadores con expectativas racionales, que actúan en mercados con fricciones nominales y competencia imperfecta, es decir, con precios que no se ajustan inmediatamente ${ }^{24}$, lo que da lugar a equilibrios con desempleo, que se pueden corregir mediante políticas fiscales y monetarias eficaces.

El siguiente paso en la evolución de los modelos macroeconómicos fue el desarrollo en los años noventa de lo que Goodfriend y King (1997) llamaron la Nueva Síntesis Neoclásica (cfr. Woodford 2009). Elementos de esa síntesis, que están presentes en muchos de los modelos actuales, son: 1) fundamentos coherentes de equilibrio general intertemporal que, por ejemplo, permiten analizar fluctuaciones a corto plazo y crecimiento a largo en un mismo marco teórico, y en los que la conducta de los agentes responde a las condiciones creadas por los otros agentes. 2) Modelos estructurales econométricamente validados, que ofrecen una descripción cuantitativa completa de los procesos estocásticos conjuntos que muestran la evolución de las variables y cuyos parámetros puedan ser estimados por comparación directa con las variables relevantes. 3) Modelos en que las expectativas son endógenas, que cumplen la condición de

Por ejemplo, Tobin (1981) la calificó de "monetarismo II".

23 Brunner y Meltzer (1972a, 838, nota 1) decían que "una visión dominante entre los economistas es que las hipótesis que impliquen regularidades empíricas deben ser 'respaldadas' por una teoría de nivel superior, de la que se pueda derivar la proposición de menor nivel. No compartimos este punto de vista; de hecho, discrepamos fuertemente (...) Por el contrario, si las teorías generan conjeturas empíricas útiles (...) aumenta el beneficio esperado de pruebas más exigentes derivadas de hipótesis desarrolladas más plenamente".

24 Rigideces que se fueron proponiendo desde los años setenta, como la existencia de contratos de trabajo, costes de menú, competencia imperfecta, precios escalonados, fallos de coordinación y salarios de eficiencia, además de las deficiencias de la información explicadas por los monetaristas. 
Lucas (1976), pero donde la existencia de rigideces permite que las políticas sean efectivas, aunque las expectativas sean racionales. 4) Las perturbaciones reales pueden ser una fuente importante de fluctuaciones económicas, y tienen efectos a través de la oferta, no solo de la demanda agregada.

Aparentemente, estos modelos no guardan relación con los monetaristas, porque no suelen incluir una función LM explícita, ni incorporan la cantidad de dinero entre sus variables ${ }^{25}$. Pero el dinero está presente de otro modo, a través de una regla monetaria como la de Taylor (1993), que recoge la reacción de los tipos de interés a la inflación y el crecimiento del producto. La inflación, por ejemplo, viene determinada por el componente sistemático de la política monetaria, y la curva de Phillips relaciona ahora la inflación corriente con el producto corriente y la inflación esperada (Roberts 1995). Por ello, Bordo y Schwartz $(2004,236)$ pueden hacer notar que, "aunque falta el dinero en el modelo macro convencional, las lecciones del monetarismo no han sido ignoradas. En el modelo se incorporan varios principios fundamentales de Friedman: que la inflación es siempre y en todas partes un fenómeno monetario y puede controlarse mediante la política monetaria; que la política monetaria a corto plazo tiene importantes efectos reales debido a la presencia de rigideces nominales o retrasos en el ajuste de la inflación esperada a la real; es decir, que a la larga la curva de Phillips es vertical y que la inflación esperada se ajusta a su nivel efectivo; que hay una distinción entre tasas de interés nominales y reales incorporadas en la ecuación de Fisher; y que las reglas de política son anclas importantes para una política monetaria estable".

Los desarrollos recientes de esta rápida evolución corresponden a los modelos dinámicos estocásticos de equilibrio general (DSGE: dynamic stochastic general equilibrium) (Clarida, Galí y Gertler 1999; Christiano, Eichenbaum y Evans 2005; Smets y Wouters 2003, 2007) ${ }^{26}$. Estos modelos generan predicciones condicionales razonables y permiten flexibilidad en el uso; aceptan que el dinero es neutral a largo plazo, pero no a corto, por las rigideces nominales, y concluyen que la política monetaria no debe usarse para obtener resultados a corto plazo en el empleo o el producto, porque esto desestabiliza las expectativas de inflación. Pero, como ya había señalado Friedman (1968a), la política monetaria puede ser útil para corregir perturbaciones externas no esperadas, especialmente si producen movimientos en la misma dirección en el producto y en los precios ${ }^{27}$.

Finalmente, se debe hacer una mención de la Nueva Economía Monetarista (Williamson y Wright
2010, 2011), que combina dos ramas de la literatura reciente: una, basada en estudios sobre la intermediación financiera y las fricciones crediticias, y otra sobre el riesgo bancario compartido, ambas de claro sabor monetarista, que se adaptan muy bien a los problemas derivados de la crisis financiera, incluyendo la posibilidad de equilibrios múltiples con tipos de interés iguales a cero (Williamson 2012, Wright 2018). Estos modelos destacan la importancia de las transacciones financieras que se llevan a cabo y los procesos de intermediación.

En resumen, ¿qué papel ha tenido el monetarismo en estos desarrollos? Una larga cita de Hetzel (2017, 9ss.) nos da algunas pistas:

Con el modelo Nuevo Keynesiano, los monetaristas lograron tener un modelo. (...) [Su] núcleo resume una economía de mercado competitiva, basada en el supuesto de que el sistema de precios funciona bien y asegura el pleno empleo de los recursos. Los hogares y las empresas tienen visión de futuro con expectativas racionales y procesan la información sobre el futuro de manera eficiente (...). El argumento monetarista a favor de una regla de política consiguió una base teórica, construida sobre la forma como la regla condiciona las expectativas sobre la política monetaria futura cuando responde de manera estabilizadora a las 'noticias' sobre la economía (...). Goodfriend y King (1997) destacaron el carácter monetarista del modelo Nuevo Keynesiano, al señalar que una política de estabilidad de precios elimina la fricción nominal que impide que la economía se comporte como una economía de mercado competitiva. Blanchard y Galí (2007) calificaron a la ocurrencia simultánea de estabilidad de precios y pleno empleo como una 'coincidencia divina'. La implicación práctica de un objetivo de estabilidad de precios es que la Fed sigue una regla que transfiere la determinación de variables reales a las fuerzas del mercado. En la literatura monetarista, el ancla nominal implicaba un equilibrio real basado en un agregado monetario dado de manera exógena (Patinkin 1965); en el modelo Nuevo Keynesiano, el ancla nominal es una política monetaria que hace que las empresas que fijan precios rígidos en dólares durante varios periodos, los fijen de tal modo que se coordinen con el objetivo de inflación del banco central. La contrapartida del objetivo de estabilidad de precios es mantener la inflación esperada igual a la meta de inflación. Con esa ancla nominal, el banco central puede controlar la tendencia de la inflación, al tiempo que permite a las empresas separar la determinación de los precios relativos de los precios absolutos. Por lo tanto, el modelo Nuevo Keynesiano encarna el espíritu de monetarismo de que el banco central puede seguir una regla que proporcio-

\footnotetext{
Aunque pueden complementarse con una ecuación adicional que permite calcular la cantidad de dinero que el banco central debe proporcionar, dada la regla de política y las perturbaciones (McCallum 1999).

26 Christiano, Eichenbaum y Trabandt (2017) citan a Friedman (1968a) como precedente de los modelos DSGE. Para una crítica de estos modelos, cf. Stiglitz (2018).

27 Pero la causalidad en estos modelos es diferente de la señalada por los monetaristas: para estos, la relación va del dinero a la inflación no esperada y de esta a la demanda y el producto, mientras que en los modelos Nuevos Keynesianos la causalidad va del dinero a la demanda, al producto y a los precios.
} 
na estabilidad económica al separar la determinación de los precios relativos del nivel de precios. Sin embargo, en el modelo Nuevo Keynesiano, la política monetaria todavía posee un fuerte poder estabilizador (...). Incluso con el límite inferior cero, la política conserva sus poderes estabilizadores porque el banco central puede comprometerse a mantener la tasa real por debajo de la tasa natural después de que esta última se vuelva positiva ${ }^{28}$.

\section{Conclusiones}

¿Dónde ha ido a parar el monetarismo? "La respuesta corta es que gran parte de esta corriente de pensamiento está todavía ahí, pero sus ideas circulan con otro nombre (...) tal vez el nombre de la Nueva Economía Keynesiana es incorrecto. Puede que no todos seamos keynesianos ahora, pero la influencia del monetarismo en cómo pensamos todos hoy en la macroeconomía ha sido profunda, generalizada y sutil" (De Long 2000, 84-85).

Sin embargo, la impresión de que el monetarismo ha fracasado está muy arraigada en la profesión. Brunner (1983, 58-59) sugiere que se trata de un problema de marketing político: "La economía política keynesiana combinada con los principales aspectos del macroanálisis keynesiano proporciona un producto altamente comercializable para el mercado político (...) El pensamiento monetarista, con su énfasis en un gobierno limitado y en la 'institucionalización' de la política, no ofrece un producto vendible a los empresarios políticos que actúan en la arena pública".

Si este diagnóstico es correcto y explica al menos una parte del "fracaso" del monetarismo, las conclusiones de nuestro análisis podrían ser: 1) El monetarismo no es, solo o principalmente, una escuela sobre el dinero y su impacto, sino que extiende sus tesis sobre cómo funciona la sociedad y, por tanto, cómo se deben gestionar las políticas económicas; 2) sus tesis sobre el dinero, la política monetaria, la inflación y las fluctuaciones económicas se han reconocido en buena parte como válidas, y han pasado a formar parte de los contenidos de la macroeconomía en general, y de la política monetaria en particular; 3) pero muchos no aceptan la tesis "fuerte" de que el conocimiento de los políticos es y será siempre li- mitado, de modo que deben aceptar restricciones en sus políticas, renunciando al activismo, cuyas consecuencias pueden ser mucho peores que lo que sus buenas intenciones prometen.

De ahí la conclusión de Laidler (1990): la propuesta monetarista de quitar poder al banco central, para evitar que se convierta en una causa de desestabilización económica, ha fracasado: esas instituciones son ahora mucho más poderosas que en los años del auge monetarista, aunque, eso sí, aceptan sujetarse a reglas flexibles y a procesos de transparencia e información que pretenden, al menos, exigir una detallada publicidad de sus decisiones ante los mercados y los expertos.

¿Es ideológica la propuesta monetarista? Para muchos keynesianos en los años de la controversia, la respuesta era afirmativa. Desde luego, los monetaristas "intentan proporcionar un marco sistemático y unificado para la comprensión de la realidad social" (Brunner 1983, 33), pero otro tanto hacen los keynesianos y, en definitiva, todas las escuelas. Puede argumentarse que esto es "ideología", pero tiene también un contenido "cognitivo" (Brunner 1983, 33) que puede analizarse y argumentarse, y en última instancia, valorarse por los resultados.

Como conclusión, recogemos una larga cita de Hetzel $(2007,24)$ sobre el cabeza de la escuela, Milton Friedman, que "se convirtió en uno de los intelectuales más influyentes en el siglo XX debido al impacto de sus ideas en la redefinición de los puntos de vista de la Depresión y en la configuración de los puntos de vista contemporáneos de la Gran Inflación desde mediados de los años sesenta hasta principios de los ochenta. Una razón importante para el éxito de Friedman como economista fue que combinó los rasgos intelectuales del teórico y el empirista. Los teóricos piensan de manera deductiva e intentan entender el mundo que los rodea en términos de algunas abstracciones. Los empiristas piensan inductivamente y tratan de entender el mundo que los rodea a través de la exploración de las regularidades empíricas. Friedman poseía ambos rasgos. El temperamento teórico de Friedman apareció en su atracción por la lógica de la economía neoclásica. Al mismo tiempo, Friedman se obligó implacablemente a formular hipótesis con implicaciones comprobables".

\section{Referencias}

Andersen, L.C. y J. Jordan. 1968. Monetary and Fiscal Actions: A Test of their Relative Importance in Economic Stabilization. Federal Reserve Bank of St. Louis Review, 50, 11-24. files.stlouisfed.org/files/htdocs/publications/review/68/11/ Monetary_Nov1968.pdf

\footnotetext{
28 La crisis financiera y la Gran Recesión han presentado nuevos problemas para los modelos macroeconómicos en los años recientes: la introducción de fricciones en los mercados financieros y en la liquidez de los bancos; la posibilidad de equilibrios múltiples, una de cuyas soluciones sea un equilibrio con bajo crecimiento e inflación muy reducida pero sin espiral deflacionista y con políticas estabilizadoras ineficaces, incluyendo pánicos de liquidez que afecten principalmente a las instituciones financieras no bancarias; la posibilidad de equilibrios inestables, en los que pequeñas perturbaciones tengan efectos cuantitativamente importantes; la existencia de shocks de riesgos; “"bucles diabólicos” entre la deuda soberana y la estabilidad de los bancos, etc. Cf. Mankiw y Reis (2018).
} 
Argandoña, A. 1981. La teoría monetaria moderna. De Keynes a la década de los 80. 2a ed. Barcelona: Ariel (1ª ed., 1972).

Argandoña, A., C. Gámez y F. Mochón. 1996. Macroeconomía avanzada I. Madrid: McGraw-Hill.

Blanchard, O. y J. Galí. 2007. Real Wage Rigidities and the New Keynesian Model. Journal of Money, Credit, and Banking, 39(1), 35-65. doi:10.1111/j.1538-4616.2007.00015.x.

Blinder, A. 2013. After the Music Stopped: The Financial Crisis, the Response, and the Work Ahead. London: Penguin Press.

Bordo, M.D y A.J. Schwartz. 2004. IS-LM and Monetarism. History of Political Economy, 36(Supl. 1), 217-239. doi: 10.1215/00182702-36-Suppl_1-217.

Brunner, K. 1968. The Role of Money and Monetary Theory. Federal Reserve Bank of St. Louis Review, 50(7), 8-24. files. stlouisfed.org/files/htdocs/publications/review/68/07/Money_July1968.pdf

Brunner, K. 1970. The 'Monetarist Revolution' in Monetary Theory. Weltwirtschaftliches Archiv, 105, 1-30. doi: 10.1007/ BF02708671.

Brunner, K., 1974, Monetary Management, Domestic Inflation, and Imported Inflation. En R.Z. Aliber (ed.), National Monetary Policies and the International Financial System. Chicago, University of Chicago Press, pp. 179-208.

Brunner, K. 1983. Has Monetarism Failed? Cato Journal, 3(1), 23-62. pdfs.semanticscholar.org/803d/c8632bec26142f4c6b54f9e692c6acf2fe72.pdf

Brunner, K. 1984, Monetary Policy and Monetary Order, Aussenwirtschaft, 39.

Brunner, K. 1989. The Disarray in Macroeconomics. En F. Capie y G.E. Wood (eds.), Monetary Economics in the 1980s. London, Macmillan, pp. 197-233. link.springer.com/chapter/10.1007/978-1-349-10149-8_9

Brunner, K. y A.H. Meltzer. 1969. The Nature of the Policy Problem. En K. Brunner (ed.), Targets and Indicators of Monetary Policy. San Francisco, Chandler, pp. 1-26. pdfs.semanticscholar.org/f591/252e40f049ba2c6d3808b62cb75608d5cccf.pdf

Brunner, K. y A.H. Meltzer. 1971. The Uses of Money: Money in the Theory of an Exchange Economy. American Economic Review, 61(5), 784-805. pdfs.semanticscholar.org/957c/d8e70ca591c17792fdfcc1c9a7bfe978464f.pdf

Brunner, K. y A.H. Meltzer. 1972a. Friedman's Monetary Theory. Journal of Political Economy, 80(5), 837-851. doi: 10.1086/259940

Brunner, K. y A.H. Meltzer. 1972b. Money, Debt and Economic Activity. Journal of Political Economy, 80(5), 951-977. doi: $10.1086 / 259945$

Brunner, K. y A.H. Meltzer. 1972c. A Monetarist Framework for Aggregative Analysis. En K. Brunner (ed.), Proceedings of the First Konstanzer Seminar on Monetary Theory and Monetary Policy. Berlin: Duncker and Humblot, pp. 31-88. pdfs.semanticscholar.org/df66/ce57c47eb5b1e21207cf3023f4b2d140d3cb.pdf

Brunner, K. y A.H. Meltzer. 1973. Mr. Hicks and the 'Monetarists'. Economica, 40(157), 44-59. doi: 10.2307/2552680

Brunner, K. y A.H. Meltzer. 1976. An Aggregative Theory for a Closed Economy. En J.L. Stein (ed.), Monetarism. Amsterdam. North Holland, pp. 69-103. pdfs.semanticscholar.org/baba/af2db59b507a9645999b0b2319c1f059bf2f.pdf

Brunner, K. y A.H. Meltzer. 1988. Money and Credit in the Monetary Transmission Process. American Economic Review, 78(2), 446-451. pdfs.semanticscholar.org/214a/c4754d3296102ba3f588a904b6e5a24a824b.pdf

Brunner, K. y A.H. Meltzer. 1993. Money and the Economy: Issues in Monetary Analysis. The Raffaele Mattioli Lectures. Cambridge: Cambridge University Press.

Cagan, P. 1956. The Monetary Dynamics of Hyperinflation. En M. Friedman (ed.), Studies in the Quantity Theory of Money. Chicago, University of Chicago Press, pp. 25-43. www.academia.edu/4690826/Cagan_-_The_monetary_dynamics of hyperinflation

Cagan, P. 1987. Monetarism. En J. Eatwell, M. Milgate y P. Newman (eds.), The New Palgrave: Dictionary of Economics, vol. 3. London, Palgrave, pp. 195-205. doi: 10.1057/978-0-230-27980-3.

Castañeda, J. y T. Congdon. 2017. Have Central Banks Forgotten about Money? The Case of the European Central Bank, 1999-2014. En T. Congdon (ed.), Money in the Great Recession. Did a Crash in Money Growth Cause the Global Slump? Cheltenham, Edward Elgar.

Christiano, L., M.S. Eichenbaum y C. Evans. 2005. Nominal Rigidities and the Dynamic Effects of a Shock to Monetary Policy. Journal of Political Economy, 113(1), 1-45. doi: 10.1086/426038.

Christiano, L., M.S. Eichenbaum y M. Trabant, 2017, On DSGE Models. NBER Working Paper 2481, www.nber.org/ papers/w24811.pdf.

Clarida, R., J. Galí y M. Gertler. 1999. The Science of Monetary Policy: A New Keynesian Perspective. Journal of Economic Literature, 37(4), 1661-1707. doi: 10.1257/jel.37.4.1661.

Cukierman, A. 1992. Central Bank Strategy, Credibility and Independence - Theory and Evidence. Cambridge: MIT Press.

De Long, B. 2000. The Triumph of Monetarism? Journal of Economic Perspectives, 14(1), 83-94. doi: 10.1257/ jep.14.1.83.

Dellas, H. y G.S. Tavlas (2018). Milton Friedman and the Case for Flexibles Exchange Rates and Monetary Rules. Cato Journal, Spring-Summer. www.cato.org/cato-journal/springsummer-2018/milton-friedman-case-flexible-exchange-rates-monetary-rules. 
Du Plessis, S., 2014, A Post-Crisis Reading of 'The Role of Monetary Policy'. Economic Research Southern Africa, ERSA Working Paper No. 419. econrsa.org/system/files/publications/working_papers/working_paper_419.pdf

Eggertsson, G.B. y M. Woodford. 2003. The Zero Bound on Interest Rates and Optimal Monetary Policy. Brookings Papers on Economic Activity, 1, 139-211. www.brookings.edu/bpea-articles/the-zero-bound-on-interest-rates-and-optimal-monetary-policy/

Fisher, I. 1920. The Purchasing Power of Money, New Edition. New York: Macmillan.

Fisher, I. 1930. The Theory of Interest. New York: Macmillan.

Friedman, B.M. 1976. Targets, Instruments, and Indicators of Monetary Policy. Journal of Monetary Economics, 1(4), 443-473. doi: 10.1016/0304-3932(76)90013-1

Friedman, B.M. 1997. The Rise and Fall of Money Growth Targets as Guidelines for U.S. Monetary Policy. En I. Kuroda (ed.), Towards More Effective Monetary Policy, Londres, Macmillan, pp. 137-164. doi: 10.1007/978-1-349-253821 6.

Friedman, M. 1953a. The Methodology of Positive Economics. En M. Friedman (ed.), Essays in Positive Economics. Chicago: University of Chicago Press, pp. 3-43. pdfs.semanticscholar.org/4af4/acabcbae145c9d21bca3cfb34fdbb55282a0.pdf

Friedman, M. 1953b. The Case for Flexible Exchange Rates. En M. Friedman (ed.), Essays in Positive Economics. Chicago: University of Chicago Press, pp. 157-203.

Friedman, M. 1956. The Quantity Theory of Money - A Restatement. En M. Friedman (ed.), Studies in the Quantity Theory of Money, Chicago: University of Chicago Press, pp. 3-21. doi: 10.1057/978-1-349-95121-5_1640-2.

Friedman, M. 1957. A Theory of the Consumption Function. Princeton: Princeton University Press. www.nber.org/books/ frie57-1.

Friedman, M. 1958. The Supply of Money and Changes of Prices and Output. En The Relationship of Prices to Economic Stability and Growth, 85 th Congress, $2^{\text {nd }}$ Session, Joint Economic Committee. Washington: U.S. Printing Office.

Friedman, M. 1959. The Demand for Money: Some Theoretical and Empirical Results. Journal of Political Economy, 67(4), 327-351. www.jstor.org/stable/1816142?seq=1\#metadata_info_tab_contents.

Friedman, M. 1960. A Program for Monetary Stability. New York: Fordham University Press.

Friedman, M. 1961a. The Demand for Money. American Philosophical Society Proceedings, 105, $259-264$.

Friedman, M. 1961b. The Lag in Effect of Monetary Policy. Journal of Political Economy, 69(5), 447-466. doi: $10.1086 / 258537$.

Friedman, M. 1962. Capitalism and Freedom. Chicago: University of Chicago Press.

Friedman, M. 1963. Inflation: Causes and Consequences. Bombay: Asia Publishing House. Reproducido en M. Friedman (ed.), Dollars and Deficits: Inflation, Monetary Policy and the Balance of Payments, Englewood Cliffs, Prentice Hall, 1968.

Friedman, M. 1966a. Interest Rates and the Demand for Money. Journal of Law and Economics, 9, 71-85. doi: $10.1086 / 466620$.

Friedman, M. 1966b. What Price Guideposts? En G.P. Shultz y R.Z. Aliber (eds.), Guidelines: Informal Controls and the Market Place. Chicago: University of Chicago Press, pp. 17-39. miltonfriedman.hoover.org/objects/57580/ what-price-guideposts

Friedman, M. 1968a. The Role of Monetary Policy”. American Economic Review, 58(1), 1-17. doi: 10.1007/978-1-34924002-9_11.

Friedman, M., 1968b, "Money, Quantity Theory”. En International Encyclopedia of the Social Sciences, New York: McMillan y Free Press, 432-447.

Friedman, M. 1969. The Optimum Quantity of Money. En M. Friedman (ed.), The Optimum Quantity of Money and Other Essays. Chicago: Aldine Publishing. doi: 10.7202/1003887ar

Friedman, M. 1970. A Theoretical Framework for Monetary Analysis. Journal of Political Economy, 78(2), $193-238$. doi: 10.1086/259623?journalCode=jpe

Friedman, M. 1971. A Monetary Theory of Nominal Income. Journal of Political Economy, 79(2), 323-337. doi: $10.1086 / 259746$

Friedman, M., 1974, Monetary Correction. IEA Occasional Paper No. 41.

Friedman, M. 1983. A Monetarist View. The Journal of Economic Education, 14(1), 44-55. doi: $10.1080 / 00220485.1983 .10845035$

Friedman, M. 1984. "Lessons from the 1979-82 Monetary Policy Experiment", American Economic Review, 74(2), 397-400.

Friedman, M. 2001. Interviewed by John B. Taylor. Macroeconomic Dynamics, 5, 101-131.

Friedman, M. y D. Meiselman. 1963. The Relative Stability of Monetary Velocity and Investment Multiplier in the United States, 1897-1958. En Commission on Money and Credit, Stabilization Policies. Englewood Cliffs, Prentice Hall, pp. 165-268. www.jstor.org/stable/1823932?seq=1\#metadata_info_tab_contents.

Friedman, M. y A.J. Schwartz. 1963a. A Monetary History of the United States, $1867-1960$. Princeton: Princeton University Press. 
Friedman, M. y A.J. Schwartz. 1963b. Money and Business Cycles. Review of Economics and Statistics, 45(2 suppl.), 32-64. www.nber.org/chapters/c7496.pdf.

Galí, J. 2018. The State of New Keynesian Economics: A Partial Statement. Journal of Economic Perspectives, 32(3), 87-112. doi: 10.1257/jep.32.3.87.

Galí, J. y M. Gertler. 2007. Macroeconomic Modelling for Monetary Policy Evaluation. Journal of Economic Perspectives, 21(4), 25-46. doi: 10.1257/jep.21.4.25.

Goodfriend, M. y R. King, 1997. The New Neoclassical Synthesis and the Role of Monetary Policy. NBER Macroeconomics Annual, 12, 231-296. doi: 10.1086/654336.

Gordon, R.J. 1990. What Is New-Keynesian Economics? Journal of Economic Literature, 28(3), 1115-1171. www.jstor. org/stable/2727103?origin=JSTOR-pdf\&seq=1\#metadata_info_tab_contents.

Hall, R.E. y T.J. Sargent. 2018. Short-Run and Long-Run Effects of Milton Friedman's Presidential Address. Journal of Economic Perspectives, 32(1), 121-134. doi: 10.1257/jep.32.1.121.

Hetzel, R.L. 2007. The Contributions of Milton Friedman to Economics. Federal Reserve Bank of Richmond Economic Quarterly, 93(1), 1-30. www.richmondfed.org/publications/research/economic_quarterly/2007/winter/hetzel.

Hetzel, R.L. 2017. What Remains of Milton Friedman's Monetarism? Federal Reserve Bank of Richmond Working Paper WP 17-09. www.richmondfed.org/publications/research/working_papers/2017/wp_17-09.

Hicks, H.R. 1937. Mr. Keynes and the 'Classics': A Suggested Interpretation, Econometrica, 5(2), 147-159. doi: $10.2307 / 1907242$

Johnson, H.G. 1971). The Keynesian Revolution and the Monetarist Counter-Revolution. American Economic Review, 61(2), 1-14. www.jstor.org/stable/1816968?seq=1\#metadata_info_tab_contents

King, R.G. y C.I. Plosser. 1984. Money, Credit and Prices in a Real Business Cycle. American Economic Review, 74(3), 363-380. www.jstor.org/stable/1804013?seq=1\#metadata_info_tab_contents

Kydland, F.E. y E.C. Prescott, 1977. Rules rather than Discretion: The Inconsistency of Optimal Plans. Journal of Political Economy, 85(3), doi: 473-492. 10.1086/260580

Laidler, D.E.W. 1990. The Legacy of the Monetarist Controversy, Federal Reserve Bank of St. Louis Review, 72(2), 4964. research.stlouisfed.org/publications/review/1990/03/01/the-legacy-of-the-monetarist-controversy/

Laidler, D.EW. 1993. The Demand for Money: Theories, Evidence, and Problems. $4^{\text {th }}$ ed., New York: Harper and Collins.

Lucas, R.E. 1972. Expectations and the Neutrality of Money. Journal of Economic Theory, 4(2), 103-124. doi: 10.1016/0022-0531(72)90142-1.

Lucas, R.E. 1973. Some International Evidence of Output-Inflation Tradeoffs. American Economic Review, 63(3), 326334. www.jstor.org/stable/1914364?seq=1\#metadata_info_tab_contents

Lucas, R.E. 1976. Econometric Policy Evaluation: A Critique. Carnegie-Rochester Conference Series on Public Policy, 1, 19-46. doi: 10.1016/S0167-2231(76)80003-6

Lucas, R.E. y T.J. Sargent. 1978. After Keynesian Macroeconomics. En After the Phillips Curve: Persistence of High Inflation and High Unemployment. Federal Reserve Bank of Boston Conference Series No. 19, pp. 49-72. www.minneapolisfed.org/research/qr/qr321.pdf

Mankiw, N.G. y R. Reis. 2018. Friedman's Presidential Address in the Evolution of Economic Thought. Journal of Economic Perspectives, 32(1), 81-96. doi: 10.1257/jep.32.1.81

Mankiw, N.G. y D. Romer. 1991. New Keynesian Economics. Cambridge: MIT Press.

Mayer, T. y P. Minford. 2004. Monetarism: A Retrospective. World Economics, 5(2), 147-185.

McCallum, B.T. 1984. Monetarist Rules in the Light of Recent Experience. American Economic Review, 74(2), 388-391. www.jstor.org/stable/1816390?seq=1\#metadata_info_tab_contents

McCallum, B.T. 1999. Issues in the Design of Monetary Policy Rules. En J.B. Taylor y M. Woodford (eds.), Handbook of Macroeconomics. Amsterdam, Elsevier. doi: 10.1016/S1574-0048(99)10036-3

McCallum, B.T. 2008. Monetarism. The Library of Economics and Liberty, https://www.econlib.org/library/Enc/Monetarism.html.

Meltzer, A.H. 1963. The Demand for Money: The Evidence from the Time Series. Journal of Political Economy, 71(3), 219-246. doi: 219-246. 10.1086/258768

Meltzer, A.H. 1987. Limits of Short-Run Stabilization Policy. Economic Inquiry, 25(1), 1-14. doi: 1-13. 10.1111/j.14657295.1987.tb00718.x

Meltzer, A.H. 1995. Monetary, Credit and (other) Transmission Processes: A Monetarist Perspective. Journal of Economic Perspectives, 9(4), 49-72. doi: 10.1257/jep.9.4.49

Meltzer, A.H. 1998. Monetarism: The Issues and the Outcome. Atlantic Economic Journal, 26(1), 8-31. doi: 10.1007/ BF02298368

Meltzer, A.H. 2001. The Transmission Process. En Deutsche Bundesbank (ed.), The Monetary Transmission Process: Recent Developments and Lessons for Europe. New York: Palgrave, 112-130, doi: 10.1057/9780230595996 4.

Meltzer, A.H. 2004. Monetarism Revisited. World Economics, 5(3), 161-164.

Patinkin, D. 1965. Money, Interest and Prices, $2^{\mathrm{a}}$ ed. New York: Harper \& Row.

Phelps, E.S. 1967. Phillips Curves, Expectations Inflation and Optimal Unemployment over Time, Economica, 34(135), 254-281. www.jstor.org/stable/2552025?seq=1\#metadata_info_tab_contents 
Phillips, A.W. 1958. The Relation between Unemployment and the Rate of Change of Money Wages in the United Kingdom, 1861-1957”, Economica, 25(100), 283-299. doi: 10.1111/j.1468-0335.1958.tb00003.x.

Prescott, E. 1986. Theory Ahead of Measurement. Federal Reserve Bank of Minneapolis Quarterly Review, Fall, 9-22. www.minneapolisfed.org/research/qr/qr1042.pdf

Roberts, J.M. 1995. New Keynesian Economics and the Phillips Curve. Journal of Money, Credit and Banking, 27(4), 975-984. doi: 10.2307/2077783.

Samuelson, P.A. y R.M. Solow. 1960. Analytical Aspects of Anti-Inflation Policy. American Economic Review, 50(2), 177-194. www.jstor.org/stable/1815021?seq=1\#metadata_info_tab_contents.

Sargent, T.J. y N. Wallace. 1975. 'Rational' expectations, the optimal monetary instrument, and the optimal money supply rule. Journal of Political Economy, 83(2), 241-254.

Schwarz, A.J. 2008. Monetary Policy and the Legacy of Milton Friedman. Cato Journal, 28(2), 255-261. www.cato.org/ sites/cato.org/files/serials/files/cato-journal/2008/5/cj28n2-9.pdf.

Schwarzer, J.A. 2018. Cost-Push and Demand-Pull Inflation: Milton Friedman and the 'Cruel Dilemma'. Journal of Economic Perspectives, 32(1), 195-210, doi: 10.1257/jep.32.1.195.

Selden, R.T. 1956. Monetary Velocity in the United States. En M. Friedman (ed.), Studies in the Quantity Theory of Money, Chicago, Chicago University Press, pp. 179-257.

Smets, F. y R. Wouters. 2003. An Estimated Dynamic Stochastic General Equilibrium Model of the Euro Area. Journal of the European Economic Association, 1(5), 1123-1175. doi:10.1162/154247603770383415.

Smets, F. y R. Wouters. 2007. Shocks and Frictions in US business Cycles: A Bayesian DSGE Approach. American Economic Review, 97(3), 586-606, doi: 10.1257/aer.97.3.586.

Stiglitz, J.E. 2018. Where Modern Macroeconomics Went Wrong. Oxford Review of Economic Policy, 34(1-2), 70-106. doi: 10.1093/oxrep/grx057.

Summers, L.H. 2014. US Economic Prospects: Secular Stagnation, Hysteresis, and the Zero Lower Bound. Business Economics, 49(2), 65-73. doi: 10.1057/be.2014.13.

Taylor, J.B. 1993. Discretion versus Policy Rules in Practice. Carnegie-Rochester Conference Series on Public Policy, 39(1), 195-214. doi: 10.1016/0167-2231(93)90009-L.

Theil, H. 1964. Optimal Decision Rules for Government and Industry. Amsterdam: North Holland.

Tobin, J. 1981. The Monetarist Counter-Revolution Today - An Appraisal. Economic Journal, 91(361), 29-42. www.jstor. org/stable/2231692?origin=JSTOR-pdf\&seq=1\#metadata info tab contents.

Williamson, S.D. 2012. Liquidity, Monetary Policy, and the Financial Crisis: A New Monetarist Approach. American Economic Review, 102(6), 2570-2605. doi: 10.1257/aer.102.6.2570.

Williamson, S.D. y R. Wright. 2010. New Monetarist Economics: Methods. Federal Reserve Bank of St. Louis Review, 92(4), 265-302. research.stlouisfed.org/publications/review/2010/07/01/new-monetarist-economics-methods.

Williamson, S.D. y R. Wright. 2011. New Monetarist Economics: Models. En B.M. Friedman y M. Woodford (eds.), Handbook of Monetary Economics, vol. 3A. Amsterdam: Elsevier, North Holland, 25-96. www.minneapolisfed.org/ research/sr/sr443.pdf.

Woodford, M. 2007. The Case for Forecast Targeting as a Monetary Policy Strategy. Journal of Economic Perspectives, 21(4), 3-24. doi: 10.1257/jep.21.4.3.

Woodford, M. 2009. Convergence in Macroeconomics: Elements of the New Synthesis. American Economic Journal: Macroeconomics, 1(1), 267-279. doi: 10.1257/mac.1.1.267.

Wren-Lewis, S. 2018. Ending the Microfoundations Hegemony. Oxford Review of Economic Policy, 34(1-2), 55-69. doi: 10.1093/oxrep/grx054.

Wright, R. 2018. On the Future of Macroeconomics: A New Monetarist Perspective. Oxford Review of Economic Policy, 34(1-2), 107-131. doi: 10.1093/oxrep/grx044. 